\title{
Mathematical Models for Evaluating the Effectiveness of State Support for the Dairy Industry
}

\author{
Mikhail K. Chernyakov ${ }^{1,{ }^{*}}$ Maria M. Chernyakova ${ }^{2}$ Irina A. Chernyakova ${ }^{1,2}$ \\ Saidmukhtor S. Mokhtarzada ${ }^{3}$
}

\author{
${ }^{1}$ Novosibirsk State Technical University, Novosibirsk, Russia \\ ${ }^{2}$ Siberian Institute of Management, Novosibirsk, Russia \\ ${ }^{3}$ Tajik state University of Commerce, Dushanbe,Tajikistan \\ *Corresponding author. Email: mkacadem@mail.ru
}

\begin{abstract}
The digitalization of agro-industrial complex in Russia is at an extremely low level due to the insufficient level of their state support. The aim of this research is to offer an original concept for the effective regulation of the agricultural sector. The methodological basis of the research is a systematic and comparative analysis, cause-and-effect analysis, observation, comparison and grouping, as well as the methodology of the innodiversification approach. The research was based on information taken from the database of the National Union of Milk Producers. A theory of paradoxical regulation is proposed, an action mechanism is developed that allows, using actual data taken from open sources, to develop digital models for regulating the parameters of the dairy industry in the Siberian Federal District and the Novosibirsk Region. The developed mechanism was taken as the basis for the design of the digital technology algorithm, based on formulas in the form of mathematical software, obtained by the method of the inno-diversification approach. Digital technologies developed on the basis of digital models made it possible to predict with a reasonable degree of certainty the probable values of industry parameters depending on the regulatory impact.
\end{abstract}

Keywords: paradoxical theory of regulation, digital model, dairy industry

\section{INTRODUCTION}

The current level of digitalization of domestic sectors of the agro-industrial complex (AIC) is at an extremely low level due to the insufficient level of their support in the form of state regulation [1]. Therefore, in order to eliminate the lagging behind of the agro-industrial complex of Russia, it is necessary to increase the volume of state support for the agro-industrial complex [2]. In its turn, in order to determine the necessary level of effectiveness of such support, it is necessary to determine the mechanism of its impact on the basic indicators of the agro-industrial complex. According to the authors, it is advisable to present such a mechanism in the form of a digital model.

The aim of this research is to propose an original concept for the regulation of the agro-industrial complex, to develop a model, mechanism and technology for its application and test them on the example of the dairy industry in one of the districts and regions of the Russian Federation. To achieve this goal, it is necessary to solve the following tasks:

1. Conduct an a priori analysis of information on regulation of the dairy industry.

2. To substantiate methods and approaches for assessing and forecasting indicators of the dairy industry, depending on the impact of regulatory parameters.
3. Test the proposed concept, approaches and mechanisms on the example of the Siberian Federal District (SFD) and the Novosibirsk Region (NR).

4. Predict the development trends of the dairy industry in the SFD and the NR depending on the volume of state support for this industry as the main regulatory parameter..

\section{RESEARCH METHODOLOGY}

The methodological basis of the research is a systematic and comparative analysis, cause-and-effect analysis, observation, comparison and grouping, as well as the methodology of the inno-diversification approach [3]. The research was based on information taken from the database of the National Union of Milk Producers [4-5].

\section{PARADOXICAL THEORY OF REGULATION}

\subsection{The concept of paradoxical theory of regulation}

To develop a digital model, it is necessary to determine the possible parameters characterizing the dairy industry. As such parameters, using the methods of economic 
interpretation, the author identified $15 \mathrm{key}$ indicators (Table 1).

To determine the possible relationship between the indicators (Table 1), it is advisable to conduct a correlation analysis, which will allow to establish not only the interrelation, but also its proximity to a linear form.

The results of correlation analysis showed a large spread of multidirectional correlation coefficients:

positive from 1 to 0.03 .

negative from -0.12 to -0.86 .

This indicates that there is not only a linear, but also an unambiguous relationship between the parameters of the dairy industry, although there is a linear relationship between its individual indicators, but there is a risk [7-8] of deviation from the predicted results. Therefore, it is not possible to establish the interrelation between the parameters using traditional methods. Thus, the authors proposed a paradoxical theory, which suggests considering the direct interrelation between the parameters, where possible, and indirect, where such an interrelation cannot be established.

Table 1. Indicators characterizing the dairy industry [4-5]

\begin{tabular}{|l|l|}
\hline Designation & \\
\hline X1 & Milk production in farms of all categories, thousand tons \\
\hline X2 & Production of marketable milk, thousand tons \\
\hline X3 & $\begin{array}{l}\text { Livestock of cows in farms of all categories at the end of the year, thousand animal } \\
\text { units }\end{array}$ \\
\hline X4 & $\begin{array}{l}\text { Livestock of cows at the end of the year in the agricultural organizations, peasant } \\
\text { farms, private subsidiary farms, thousand animal units }\end{array}$ \\
\hline X5 & $\begin{array}{l}\text { Proportion of brood cows in the agricultural organizations, peasant farms, private } \\
\text { subsidiary farms, \% }\end{array}$ \\
\hline X6 & Proportion of brood cows of milk and mixed production, \% \\
\hline X7 & Milk production of cows in farms of all categories, $\mathrm{kg} / \mathrm{year}$ \\
\hline $\mathrm{X} 8$ & Milk production of cows in agricultural organizations (AO), $\mathrm{kg} / \mathrm{year}$ \\
\hline $\mathrm{X} 9$ & Milk production of cows in peasant farms (PF), kg/year \\
\hline $\mathrm{X} 10$ & Milk production of cows in private subsidiary farms (PSF), kg/year \\
\hline $\mathrm{X} 11$ & Milk production of brood cows, kg/year \\
\hline $\mathrm{X} 12$ & Production of milk and dairy products per capita, kg/year \\
\hline $\mathrm{X} 13$ & Consumption of milk and dairy products per capita, kg/year \\
\hline $\mathrm{X} 14$ & Milk processing and production of dairy products recalculated as milk, tons \\
\hline $\mathrm{X} 15$ & Volume of state support funds for the dairy industry, mln. RUR \\
\hline
\end{tabular}

\subsection{Paradoxical regulatory model}

Based on the conducted a priori analysis, the authors proposed a hypothesis that assumes the existence of a multi-level model, which with a sufficient degree of accuracy will be able to describe the interaction of the parameters characterizing such a diverse industry as the dairy one [6].

Based on the given task, conditions and restrictions imposed when solving it, the authors admit the existence of a four-level model of the following proposed configuration for the types of interaction of indicators of the dairy industry, the structure of which is shown in Figure 1.

\subsection{The implementation mechanism of the paradoxical model}

The mechanism for implementing a multilevel model of stepwise interaction is shown in Figure 2. In the "Initial 
parameter (one or several) is assigned, the effect of which on other indicators is subject to analysis. data" block (Figure 2), information on the number of parameters studied $(\mathrm{K})$, analysis time periods $(\mathrm{P})$, and the matrix $\mathrm{X}(\mathrm{K}, \mathrm{P})$ of the values of each parameter in time intervals is inputted. In the "Regulator selection" block, a

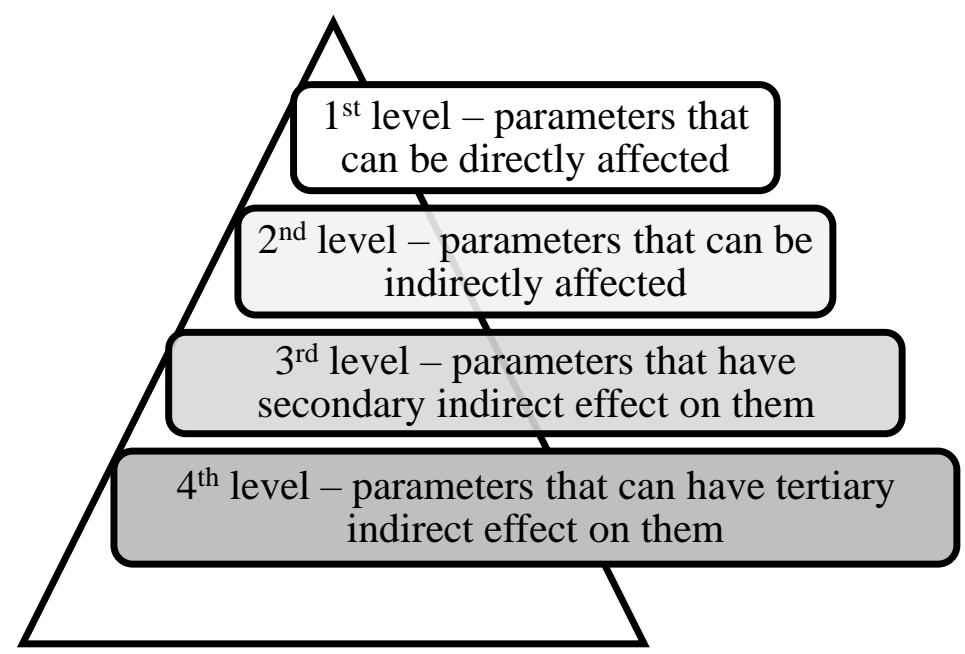

Figure 1. The four-level model of the relationship between the parameters of the dairy industry

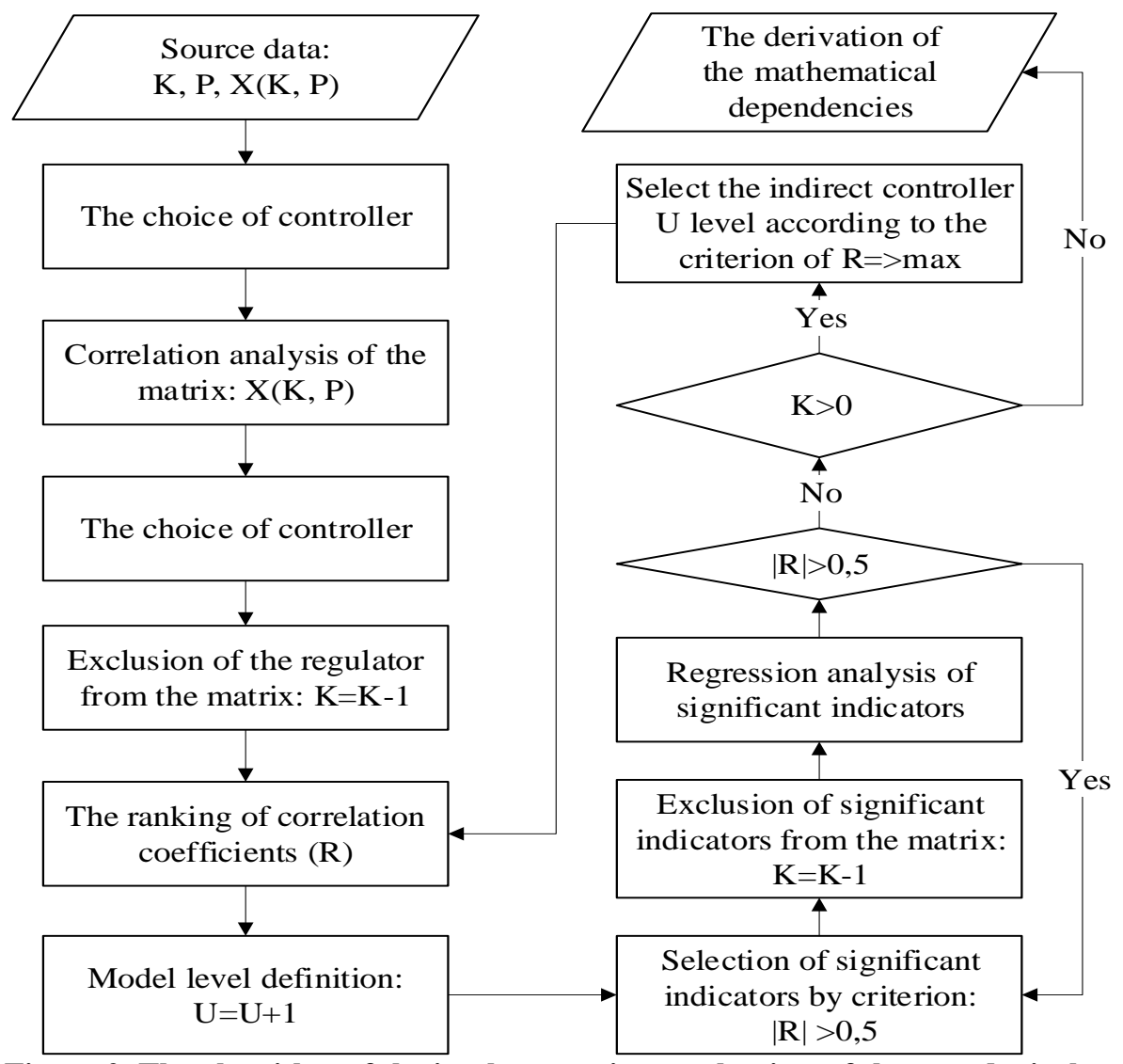

Figure 2. The algorithm of the implementation mechanism of the paradoxical model

\section{RESEARCH RESULTS}

Using the regression analysis technique, we can obtain the relationship between the main parameters in the form of a linear function. The digital technology algorithm for predicting the results of regulating the parameters of the dairy industry in the SFD is shown in Figure 3, and the NR - in Figure 4. 


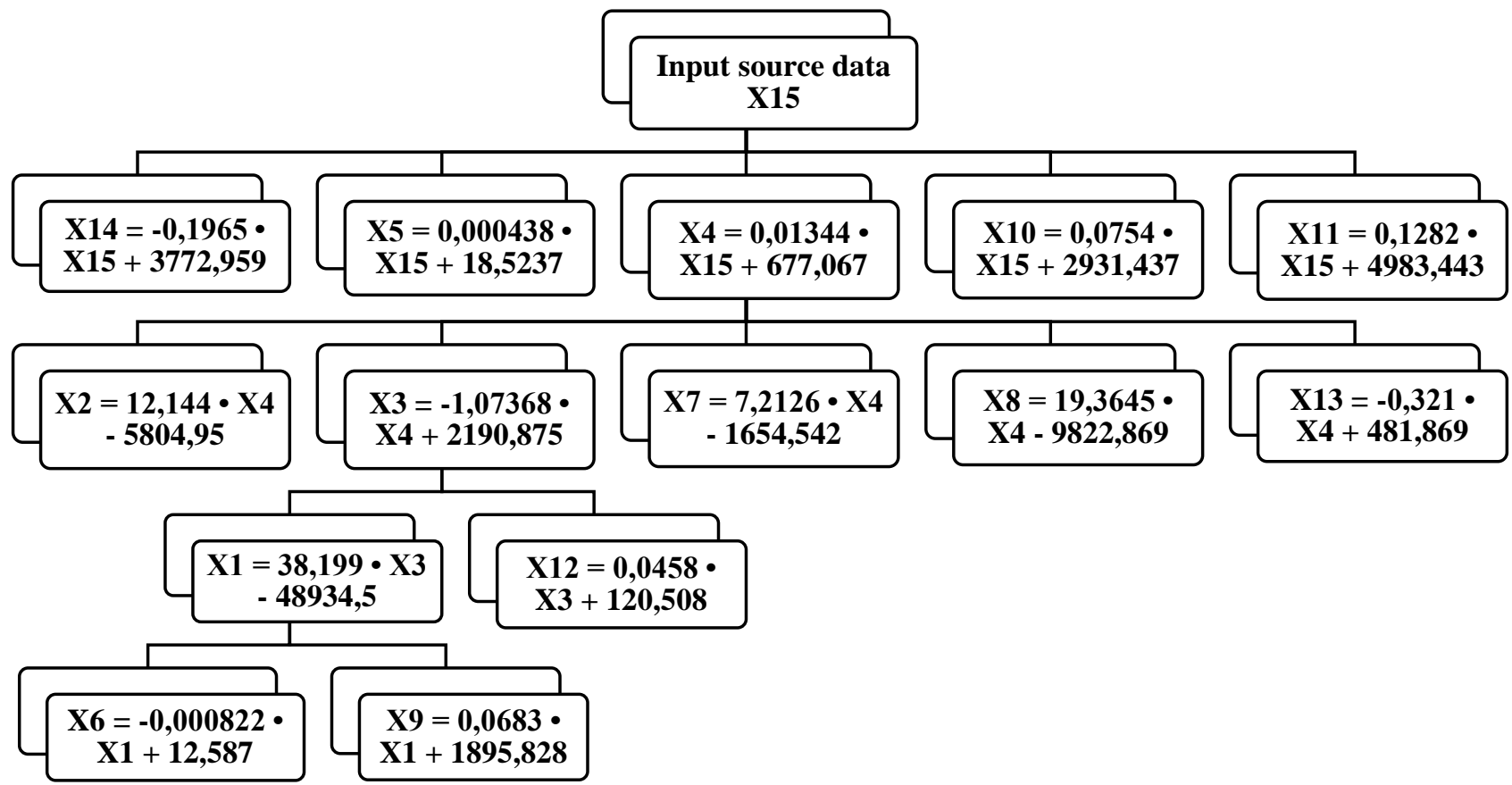

Figure 3. Algorithm of the model for the interrelation of the parameters of the dairy industry in the SFD

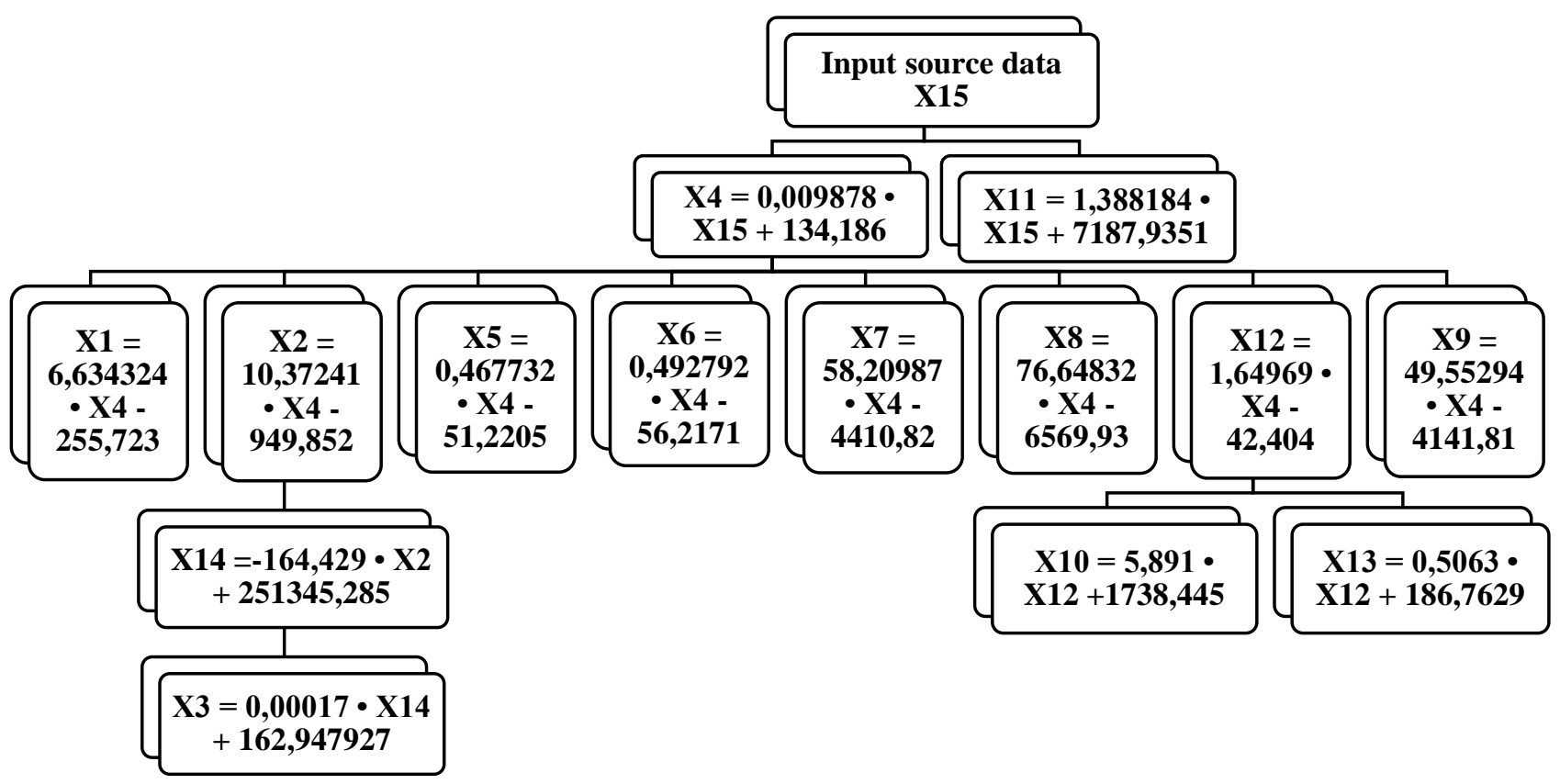

Figure 4. Algorithm of the model for the interrelation of the parameters of the dairy industry of the NR

As a result of designing digital model algorithms for regulating the parameters of the dairy industry in the SFD and NR, both general patterns and specific features were established.
Digital technologies developed on their basis made it possible with a sufficient degree of reliability (deviations did not exceed $10 \%$ ) to predict the likely values of the industry parameters depending on the regulatory impact. 


\section{DISCUSSION OF THE RESEARCH RESULTS}

A direct forecast of indicators of the dairy industry in the region has been developed. In contrast to the existing developments, the forecast is based on the use of not only a temporary factor, but also the amount of state support funds in three scenarios of the industry's development: pessimistic, expected and optimistic.

Forecasting results for 2019 showed that a decrease in the state support could lead to a sharp deterioration of the situation in the dairy industry of the NR. Maintaining financing at the same level can only slow down its decline. This indicates an acute current underfunding of the dairy industry by the state authorities. The situation may change for the better with an increase of the state support funds at least in two times compared to current funding.

A reverse forecast has been developed for the necessary volumes of state support to achieve the targeted indicators for the dairy industry at any level of effect.

To achieve the recommended rational consumption rate (of milk and dairy products recalculated as milk) 325 $\mathrm{kg} /$ year/person, allocation of state support funds in the amount of 5,773 mln RUR will be required. and, as a result, occasionally will lead to an increase in the annual production of milk and dairy products per capita up to 273 $\mathrm{kg} /$ person. and an increase of 46 thousand animal units of livestock of cows at the end of the year in agricultural organizations, peasant farms, private subsidiary farms. It is unlikely to achieve such a result in one year; therefore, the calculated amount of funds will need to be distributed over several years. With the optimistic development of the scenario, it will be possible to achieve the recommended rational consumption rate (of milk and dairy products recalculated as milk) in the NR not earlier than after four years, and with the expected scenario after 8 years. However, the estimated time frame will vary depending on the actual amount of state support funds allocated. Digital technology allows you to make appropriate adjustments depending on regulatory effects. If we exclude from the calculations the factor of regulatory effect from the volume of state support and leave only the time one, then it will be possible to achieve the recommended rational consumption rate (of milk and dairy products recalculated as milk) in the NR no earlier than 30 years later (pessimistic option).

\section{CONCLUSION}

Based on the proposed theory of paradoxical regulation, a mechanism of action was developed that made it possible, using evidence taken from open sources, to develop digital models for regulating the parameters of the dairy industry in the SFD and NR.

The developed mechanism was the taken as a basis for the design of the digital technology algorithm, based on formulas in the form of mathematical software, obtained by the method of the inno-diversification approach.
As a result of designing digital model algorithms for regulating the parameters of the dairy industry in the SFD and NR, both general patterns and specific features were established. The regulators of direct and indirect effects are the same, and differences arise only at the lower levels of interaction.

Digital technologies developed on the basis of digital models made it possible to predict with a reasonable degree of certainty the probable values of industry parameters depending on the regulatory effect [9].

Direct and reverse forecasts of indicators of the dairy industry in the region have been developed. In contrast to existing developments, the forecast is based on the use of not only a temporary factor [10], but also the amount of state support funds in three scenarios of the industry's development: pessimistic, expected and optimistic.

The proposed theory of paradoxical regulation should be applied not separately, but in combination with simulation modeling of the scenario approach [11]. Testing the proposed paradoxical theory of regulation is supposed to be carried out in other sectors and regions.

\section{ACKNOWLEDGMENT}

The article was prepared with the financial support of the Novosibirsk State Technical University (project C19-12).

\section{REFERENCES}

[1] Strategiya razvitiya pishchevoy i pererabatyvayushchey promyshlennosti Novosibirskoy oblasti na period do 2025 goda [The development strategy of the food and processing industry of the Novosibirsk region for the period until 2025], 48 p.

[2] M.K. Chernyakov, M.M. Chernyakova, Molochnaya industriya kak strategicheskoye napravleniye razvitiya rynka prodovol'stviya [Dairy industry as strategic direction of development of the market of food], Pishchevaya promyshlennost' [Food industry], 2018, № 4, pp. 33-37.

[3] Khramtsov A. New Technological Paradigm of the Russian Dairy Industry: Formation Principles Under Globalisation, Foods and Raw Materials, 2019, Tom: 7, Vol. 2, Pp. 291-300.

[4] Belov A.S., Voronin A.A., Zhebit M.E., et al., Molochnaya otrasl'-2018-2019: [spravochnik] [Dairy industry-2017 [encyclopedia]], Moscow, Natsional'nyy soyuz proizvoditeley moloka, 2017, 388 p.

[5] Belov A.S., Voronin A.A., Zhebit M.E., et al., Molochnaya otrasl'-2017: [spravochnik] [Dairy 
[9] Osipov, V.S.; Bogoviz, A.V., Transition to digital

industry-2017 [encyclopedia]], Moscow, Natsional'nyy soyuz proizvoditeley moloka, 2017, $380 \mathrm{p}$.

[6] Surovtsev V.N., Improving competitiveness of milk production on the basis of digital and biotechnologies synergy, Journal of Dairy and Beef Cattle Breeding, 2019. Vol. 4, Pp. 7-11.

[7] M.K. Chernyakov, M.M. Chernyakova, K.Ch. Akberov, Dynamic model of social risks in the digital economy, Advances in Economics, Business and Management Research, 2019, Vol. 81, Modern Management Trends and the Digital Economy: from Regional Development to Global Economic Growth: 1 intern. sci. conf. (MTDE 2019): 373-378.

[8] Song Ying-Hua, Yu Hui-Qin, Lava Wei. Risk analysis of dairy safety incidents in China, Food, 2018, № 92, pp. 63-71. agriculture: background, road map, possible consequences, Ekonomika sel'skogo khozyaistva Rossii, 2017, Vol. 10, Pp. 11-15.

[10] Kuzin A. A.; Medvedeva N. A.; Zadumkin K. A., Development Scenarios for Russia's Dairy Industry, Economic and social changes-facts trends forecast, 2018, Vol. 11, № 6, pp. 73-88.

[11] M. K. Chernyakov, M. M. Chernyakova, K. C. Akberov, Simulation design of manufacturing processes and production systems, Advances in Engineering Research. - 018, Vol. 157: Actual issues of mechanical engineering, AIME 2018, Novosibirsk, 19-21 April 2018: 124-128. 